\title{
OTERS' PREFERENCES IN BUCHAREST, ROMANIA - CHANGES AND TRENDS IN PRESIDENTIAL ELECTIONS
}

DOI: http://dx.doi.org/10.18509/GBP.2020.68

UDC: 328.13:342.843.1(498)

\author{
Alina Viorica Dumitrascu ${ }^{1}$ \\ Vasile Pop ${ }^{2}$ \\ Irina-Valentina $\operatorname{Radoi}^{3}$ \\ Camelia Teodorescu ${ }^{3}$ \\ Andrei Ducman ${ }^{3}$ \\ ${ }^{1}$ University of Bucharest, Faculty of Geography, \\ Department of Geomorphology; Bucharest, Romania \\ ${ }^{2}$ St. Elefterie Church, Bucharest, Romania \\ ${ }^{3}$ University of Bucharest, Faculty of Geography, Department of Human and Economic \\ Geography; Bucharest, Romania CAIMT (Research Center for Integrated Analysis and \\ Territorial Management), University of Bucharest, Romania
}

\begin{abstract}
The presidential elections in Romania, record, most often, different results in the urban environment compared to the rural one. Bucharest, within the 30 years since the fall of the communist regime, has produced results that have demonstrated the clear desire of the voters from a certain post-communist stage of the presidential elections. The study is based on analyzing the results from all the post-communist presidential elections, on administrative units, that is, on the six constituent sectors of Bucharest. The method of analysis resides in tracking the statistical data provided by BEC correlated with the empirical results obtained by questionnaires carried out by us, in each sector. This additional analysis allows us to obtain the data regarding the reason that determined the election of a candidate for the position of president of Romania. The results confirm the relationship between the reason for the election and the political belonging of the candidates, both in the first round, as well as on what concerns the final result obtained in the second round. Bucharest remains a 0reference milestone in terms of political orientation and openness to democracy and European politics. Bucharest, as a resident population of a large city, wants an opening to what liberal politics and European democracy offer. Regarding the structure by age and socio-professional groups or as a level of education, Bucharest voters demonstrate the most balanced values. These very values are an indicator of the tendency of liberalism in presidential elections.
\end{abstract}

Keywords: presidential elections, political regime, liberalism, democracy, urban environment

\section{INTRODUCTION}

Bucharest was an important ambassador of the fall of communism, in the 1989 Revolution, so that it is extremely interesting to analyze and identify the tendency of Bucharest to move away from a communist ideology [2], [5], [6], [9]. Since 1990 until the present time, we could say that the fight for a president's mandate, from round 2, has been constantly held between a candidate of the social-democratic ideology and a candidate of the liberal doctrine. Thus, the Bucharest people had a choice between the 
two doctrines, and an extremely important element that will be exposed in this research is related to the reason why they chose a doctrine for the most part [1], [3], [10]. There are various factors that have influenced the struggle for the position of president of Romania, but through this analysis, we will observe the factors that have influenced this phenomenon at the level of the city of Bucharest. It is well known that Bucharest is the most diverse city in terms of age categories, level of education or socio-professional categories, which is why an electoral tour can be very easily influenced by a large presence of a certain category. In order to make the analysis as relevant as possible, starting with 2009, the BEC provided data for each sector of Bucharest, we can analyze the differences reported within the municipality much more easily. Another extremely relevant aspect for research, by questioning people, $62 \%$ of them offered us as the main reason for having chosen a candidate, the very doctrine of that particular party/ the party ideology [8], [7], [4]. Thus, we can point out that in choosing a candidate, the party represented by him is taken into account, his name constituting a secondary matter in points of importance. However, $43 \%$ of Bucharest supporters argue that the candidate's background is very important, as he/ she should not be included on a list of law-breakers or criminals.

\section{METHODOLOGY}

The research was carried out in two ways: the analysis of the official electoral data offered by the BEC, together with the questioning of the Bucharest people on how they vote, the sources from which they get their information, the ideology they support, the educational level, the socio-professional category, as well as factors that may influence the choice of a candidate/party. In our research we analyzed the presidential elections of 1990, 1992, 1996, 2000, 2004, 2009, 2014 and 2019, based on the data provided by the BEC. The total number of questionnaires completed by our team is 211 unique questionnaires, and the areas in which the answers have been obtained are from all sectors of Bucharest. The most important element of the questionnaires is the fact that only people who have their domicile in Bucharest were polled, have voting rights for the local elections and can be entered on the voting lists of the Bucharest municipality on the permanent lists.

\section{RESULTS}

The year 1990 is an important milestone in the recent history of Romanians, due to the fact that it was the first year in which Romanians had the right to vote after the fall of communism. Thus, the presidential elections of 1990 were carried out in a single round, given that the representative of the FSN party, Ion Iliescu, obtained $85.07 \%$ of the votes. At that time, the data for Bucharest were centralized together with the data of Ilfov county, and the analysis can be affected, as there is no data at the level of the capital city. However, the people of Bucharest and the Ilfovians gave their confidence to the candidate of social-democratic ideology (Ion Iliescu - FSN), mainly because of his image as ambassador of the Revolution of 1989. From the friendly discussions with people who had the right to vote in 1990, they communicated to us the fact that the propaganda carried through the TVR was relevant for those elections, and the data about the other candidates were decisive. The counter-candidates of Ion Iliescu, Radu Câmpeanu and Ion Rațiu, did not live very much in Romania during the communist period, so at the country level there were doubts about their intentions. This reluctance towards the outside was also felt in these elections, and the people voted $76.72 \%$ for the social candidate - Democrat. The 
main factor of choice was represented by the image, since then, of the candidate Ion Iliescu, seen as a promoter of democracy and justice in Romania. Liberal candidates Ion Rațiu and Radu Câmpeanu together obtained 23.28\% of the votes (figure 1).

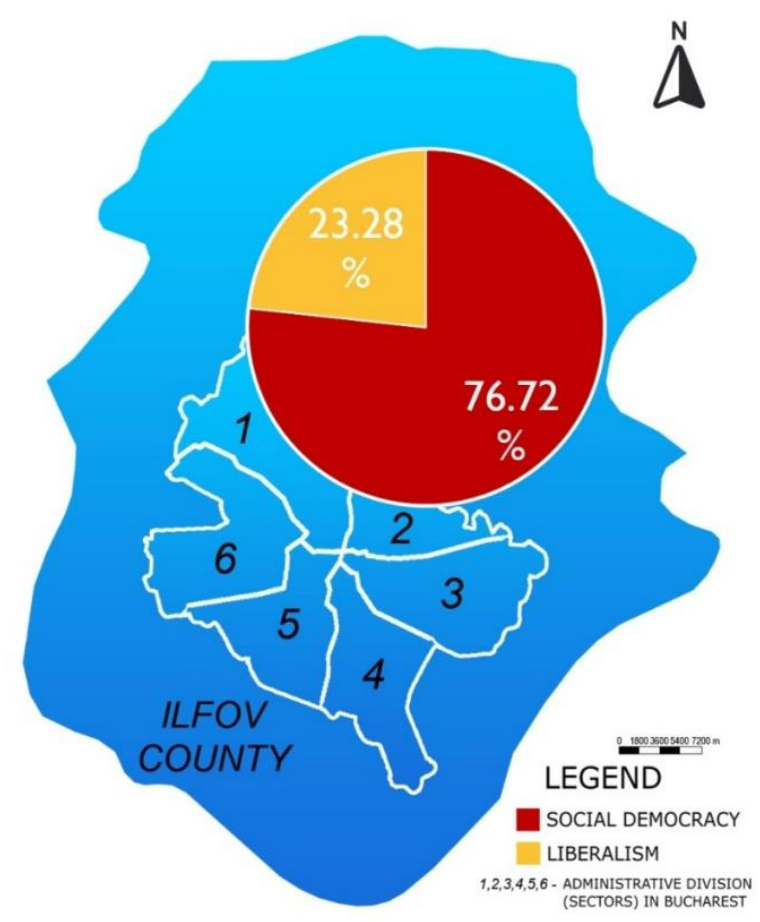

Figure 1. The results of the 1990 presidential elections for Bucharest and Ilfov

With the passing of the two years from the event known as the "Romanian Revolution", the balance was equilibrated the presidential results in Bucharest, with no major difference between the two doctrines. Thus, we can see that the social-democratic doctrine won with a ratio of $52.10 \%$, also represented by the candidate Ion Iliescu (FDSN). An important event since 1990, immediately after the elections of that year, was represented by the "Miners' rebellions from Bucharest", when the protesters from IMGB were protesting in the University Square, and at the urging of Ion Iliescu were brought 4 trains of miners from Petrosani and Motru to the capital-city in order to influence the protests. The Bucharestians considered that Ion Iliescu created a major problem in Bucharest by calling them, and his attitude of gratitude towards them led to the decrease of the Bucharestians's confidence in the social-democratic candidate. However, the majority of the people of Bucharest offered their confidence to the social- democrate candidate, disfavoring Emil Constantinescu (PNȚCD), candidate of the right forces (figure 2).

The 1996 elections find the same situation as in 1992, through the same candidates in round 2, but now in Bucharest, the winner was the liberal candidate. Emil Constantinescu (PNT,CD) has gained the confidence of over 62\% of Bucharest. The economy of the country was in a continuous decline, and the Romanian LEU/ RON (currency unit) was going through a very serious period of devaluation, this being felt in Bucharest, the capital city of the country.

People considered that the social-democratic ideology was not what they wanted further, and on the background of an aggressive movement in the country against the socialdemocratic candidate, as well as the ideology, the liberal candidate dominated the 
elections in the country, but also in Bucharest. The election campaigns of that time were very much developed in the newspapers, and the most read newspapers in Bucharest supported the liberal candidate, for example "Evenimentul Zilei", which dedicated the first page to the liberal candidate in some editions. Various ethnic minority associations and communities in Bucharest expressed their desire to support the liberal candidate, the newspapers relied on different slogans to discredit the social candidate - democrats, more and more exposed practices of the social party - democrats attracting and forcing people to vote for them, and this was decisive in these elections. Another important reason that led people towards liberalism was the debate between the two candidates and the promotion of the idea, by the newspapers, that Ion Iliescu would be an atheist. It is well known that Romanians are very close to religion, and this aspect influenced the elections. The newspapers were dominated by different reports on less known events in the candidates' lives, by the possibility of joining NATO (figure 3)

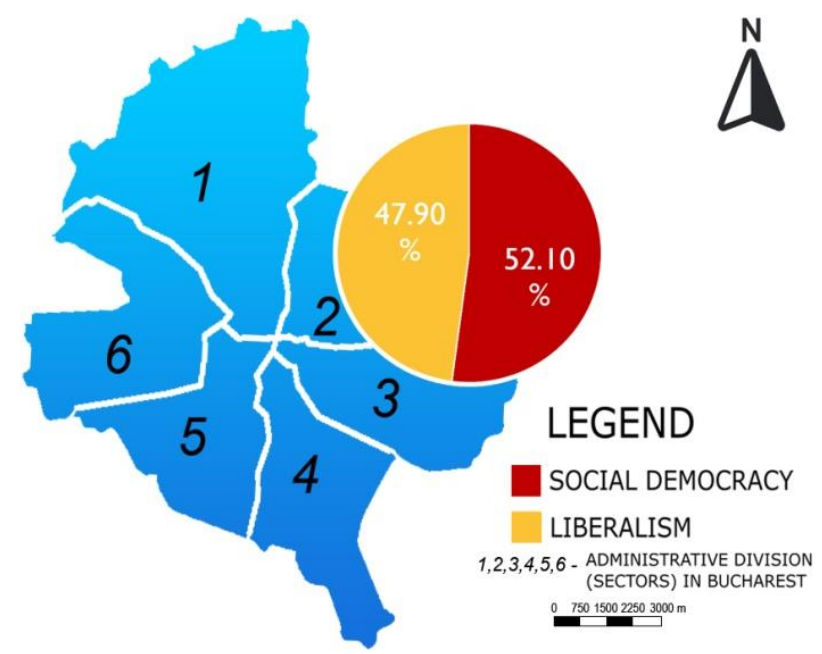

Figure 2. The results of the 1992 presidential elections for Bucharest

The year 2000 was the period in which the social-democratic party gained power again, again through candidate Ion Iliescu (PDSR). However, the context of round 2 was extremely interesting, due to the fact that in Bucharest, as well as in the country, the main reasons for this choice are the desir not to win the Liberal candidate (Corneliu Vadim Tudor), and the disappointment caused by the former Liberal mandate President Emil Constantinescu. The economic crisis of 1996 - 2000 was put on the account of the Romanian leadership by a liberal candidate, and since the 2000s people have started a process of technology progress and a desire to find out more information through the Internet. Newspapers were losing importance over time, but they were still relevant in the election campaign. The associations that used to express their desire to vote with liberalism in the past, have gone on now to promote the social - democrat candidate, due to the attitude of the candidate Corneliu Vadim Tudor towards them. The extremist, racist and xenophobic statements of the liberal candidate, the desire of not joining the European Union were decisive in the election. However, it is useful to specify that there was a very small number of voters, which is easily understood by the negative advertisement carried by all sources of information against the two candidates (figure 4). 


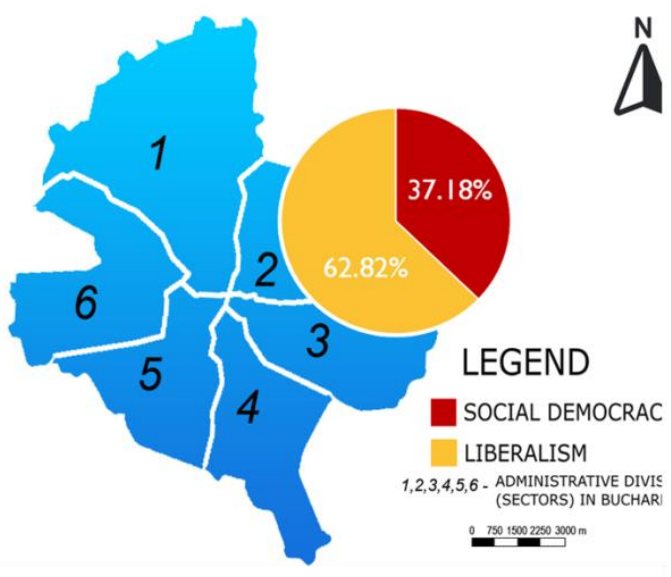

Figure 3. The results of the 1996 presidential elections for Bucharest

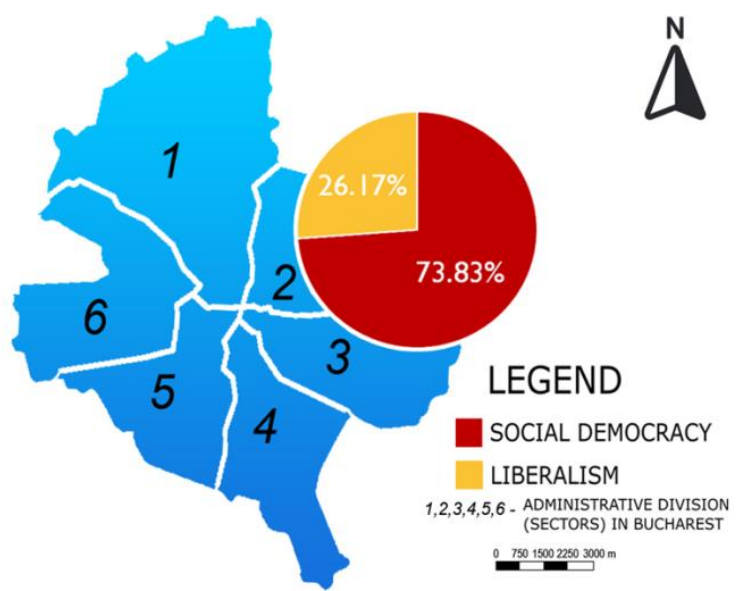

Figure 4. The results of the 2000 presidential elections for Bucharest

The year 2004 started with the promotion of the election campaign for candidates Adrian Nastase (social-democratic doctrine) and Theodor Stolojan (liberal doctrine), but just two months before the election, Theodor Stolojan resigned and propeled candidate Traian Basescu (D.A.). The liberal campaign was carried out by discrediting the government of Adrian Nastase, the main counter-candidate. People considered that Adrian Nastase carried out a false electoral campaign, obtaining votes through the most vulnerable age groups and in the socio-professional categories where the incomes did not exist or were very small. Also, the Bucharest people were very receptive to the campaign of the liberal candidate, which was promoted by the Romanian intellectuals. The desire of the liberal candidate to orient himself to the future obtained $63.40 \%$ of the votes of Bucharest, to the detriment of the orientation towards the past and achievements of the social-democratic candidate (figure 5).

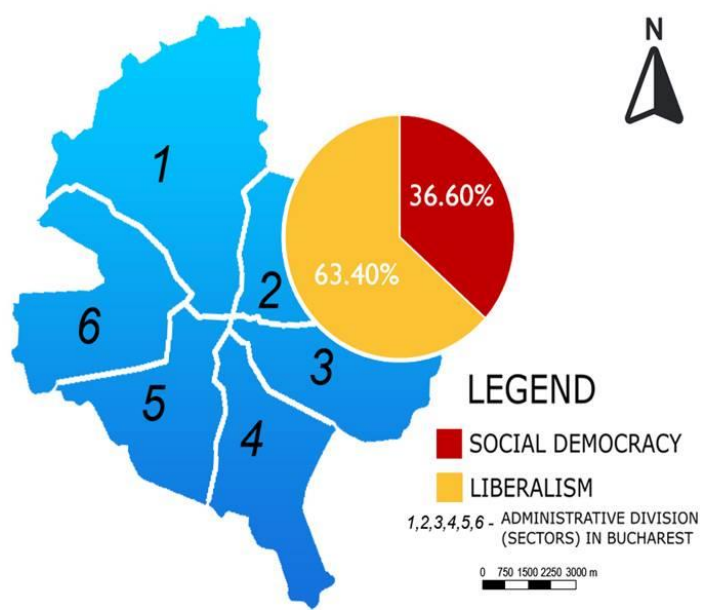

Figure 5. The results of the 2004 presidential elections for Bucharest

The promotion through the television and the Internet was gaining importance, and the newspapers were losing relevance. The political television stations were mostly owned by politicians, so they presented a high dose of subjectivism, and the candidates took advantage of their presence in their favorable positions. In 2009, there were videos designed to discredit Traian Basescu (liberal candidate), and the Bucharest people were strongly influenced by these means of discreditation. The final debate brought the Liberal candidate (Traian Basescu - PNL) and the Social Democrat candidate (Mircea Geoană - 
PSD) in front of the millions of Romanian TV channel spectators, occasion in which the Liberal candidate offered information that decisively influenced the campaign, mainly due to the way the social- democrat candidate behaved in this new context. The year 2009 is the year that offers data by sectors, so we can see that the social-democratic doctrine has dominated Bucharest, winning in 4 sectors, but at a small distance from the liberal doctrine. What counted on the sectors in Bucharest is the fact that the mayors of the respective sectors carried out the electoral campaign in each sector they actually dealt with and thus promoted their doctrine/party, which led to winning the elections. For example, Sector 2, Sector 4, Sector 5 and Sector 6 were won by the social-democratic party, due to the membership of the mayors and the campaign produced by them. Aspect also identified in sector 3, where the mayor was offered by a liberal party, and thus the doctrine was promoted accordingly (figure 6).

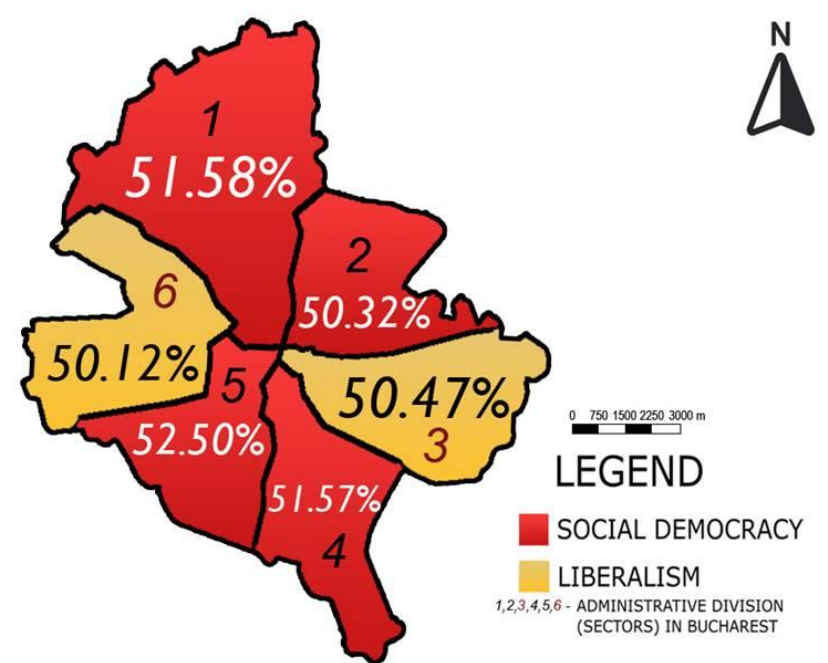

Figure 6. The results of the 2009 presidential elections for Bucharest

Starting with 2014, the election campaigns focused in the largest proportion on the online environment, to the detriment of television and newspapers. The online environment had become a promoter of events and information, so the most important news in real time were announced here. The Liberal PNL party focused online in the 2014 campaign and in 2019, so the issues are common. The liberal party has used the power of people to become opinion-makers and has realized the importance of human-to-human promotion, to the detriment of mass promotion, without a logical promotion or sample thread. The direct power of politicians, journalists, newspapers and television stations has decreased drastically, so people have become promoters. This was the secret by which Klaus Iohannis (Liberal candidate) dominated the 2014 elections, thus eliminating the negative, defamatory, permanent campaign carried out by the social- democratic candidate (Victor Ponta - PSD). The same thing was carried out in 2019, but what is important to note is that between 2014 and 2019, most of the government was social - democratic. The disappointment of the people regarding the weak governance, the large number of protests, the tragic "Collective" event, the unmasking of the corruption at the governmental level were the main causes pointed out by Bucharestians which led to the loss of credibility by the Social Democrats. The years 2014 and 2019 brought the clear victories of the liberal ideology in Bucharest, gaining with great weights in almost all sectors in both years. Interesting to see is that the candidate Klaus Iohannis has increased the confidence level of people from 2014 to 2019 in all sectors, and the sector with the 
lowest proportion of liberalism is Sector 5, being the weakest economic one in Bucharest (figure 7 and figure 8).

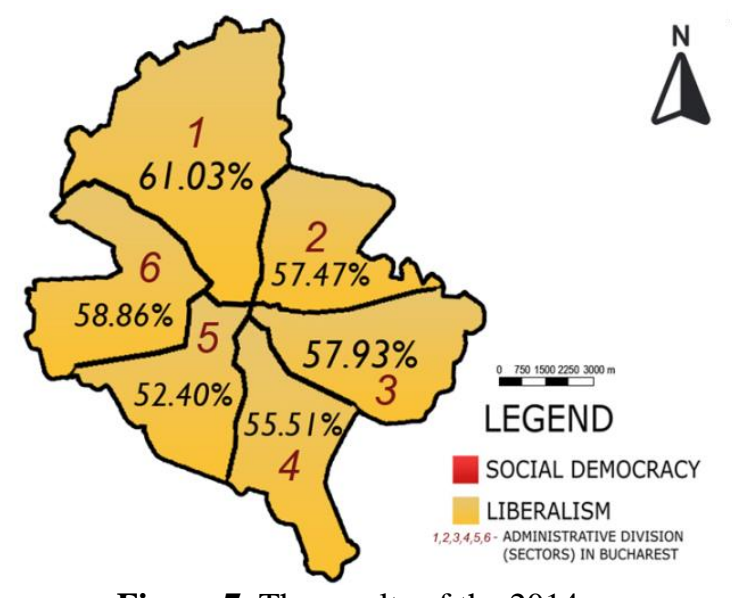

Figure 7. The results of the 2014 presidential elections for Bucharest

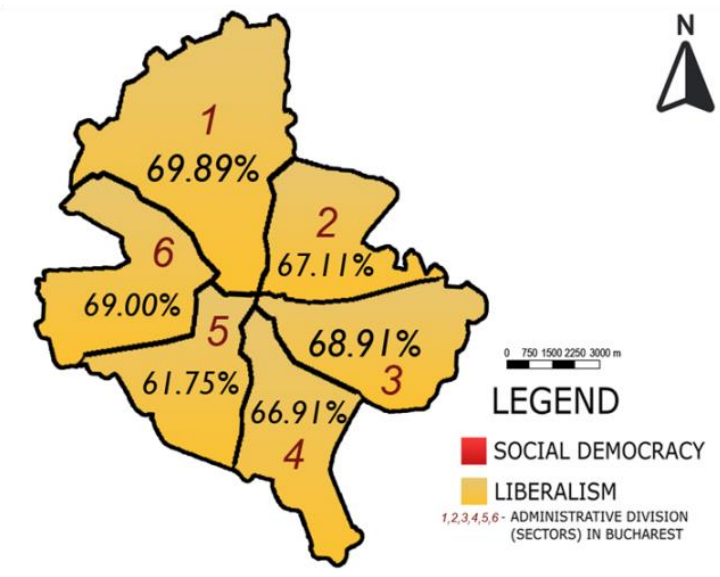

Figure 8. The results of the 2019 presidential elections for Bucharest

\section{CONCLUSIONS}

Finally, we can conclude that Bucharest has gone through a clear stage of liberalization, and the social-democratic ideology, through a series of negative events, has been discredited in front of Bucharest. At the same time, of vital importance it is the importance of information distribution channels, their objectivity, as well as the candidate's need to maintain their image as best as possible in order not to be discredited. In the questionnaires done, we were able to identify a close relationship between the $65+$ age category in Bucharest and the social-democratic ideology (68\% of the people over $65+$ years prefer the social-democratic ideology), as well as between the people in Bucharest who are unemployed and getting social aids, and social - democratic ideology (66\% of people in vulnerable socio - professional categories prefer social - democratic ideology). Also, the people in a minority argue that they are fluctuating in terms of supporting a party, depending on how they are viewed by the respective parties and the importance of the minority for the party $(51 \%$ of the respondents in a minority ethnic group do not have a favorite ideology. Last but not least, there should be outlined the capacity of the online environment and the efficiency of a campaign conducted mostly in the online environment, but also the way in which the Bucharest people react to the need to choose between two unfavorable candidates, through a vote presence in a small number and the election of the candidate who does not present extremist ideas or negative background.

\section{REFERENCES}

[1] Canavilhas Joao, Bittencourt Maira \& Augusto De Andrade, Marco Antonio, Viral Content on Facebook: a case study on the run-up to Brazilian 2018 presidential elections, Brazilian Journalism Research, vol. 15, issue. 3, pp 562-589, 2019.

[2] Dincă Iulian \& Camelia Teodorescu, The Romanian rural space and its landscapes: attraction and motivation for relocating townspeople, Geographia Napocensis, vol. 1, pp 21-36, 2015.

[3] Ekstrom Pierce, Smith Brianna, Williams Allison \& Kim Hannah, Social Network Disagreement and Reasoned Candidate Preferences, American Politics Research, vol. 48, issue. 1, pp 132-154, 2020. 
[4] Franz Michael, Fowler Erika Franklin, Ridout Travis \& Wang Meredith Yiran, The Issue Focus of Online and Television Advertising in the 2016 Presidential Campaign, American Politics Research, vol. 48, issue. 1, pp 175-196, 2020.

[5] Grecu Alexandra, Andreea Karina Gruia, Marian Marin, Mariana Bănuță, Cosmin Olteanu, Ionuț Constantin, Mihaela Gadoiu, Camelia Teodorescu, Răzvan Cătălin Dobrea \& Cristian Constantin Drăghici, Specificity of Sustainable Structural Dynamics of Local Economy in Romanian Tourist Resorts, Sustainability, vol. 11, issue.24, pp 7155 - 7167, 2019.

[6] Hill Seth, Hopkins Daniel \& Huber Gregory, Local demodra[phic changes and US presidential voting, 2012 to 2016, Preceedings of the National Academy of Science of the United States of America, vol. 116, issue. 50, pp 25023-25028, 2019.

[7] Pintilii Radu-Daniel, Daniel Peptenatu, Ana-Maria Ciobotaru, Sorin George Toma, Ana Maria Grigore, Cristian-Constantin Drăghici, Răzvan-Cătălin Dobrea, Adrian Gabriel Simion, Ion Andronache, Camelia Teodorescu \& Daniel Constantin Diaconu, Creative economies in Romania-spatial projections and trends, Bulletin of Geography. Socio-economic Series, Poland, vol. 37, pp 95-108, 2017.

[8] Szemkovics Laurentiu-Stefan, Teodorescu Camelia, Alexandra Grecu, Karina Gruia, Alina Mareci \& Nicoleta Bira, The relevance of the historical monuments in the development of the cultural tourism in the main cities of the region of Oltenia, Romania, Quaestus Journal, Timisoara, Romania, vol. 12, issue. 2, pp 42-54, 2018.

[9] Teodorescu Camelia \& Szemkovics Laurentiu-Stefan, The Ethno-creativity in the Pilot Centers in Romania and their Role in the Development of Cultural Tourism and the Educational Process, Forum geografic Geographical studies and environment protection research, Craiova, Romania, vol. 16, issue.1, pp 88-97, 2017.

[10] Van Steenburg Eric \& Guzman Francisco, The influence of political candidate brands during the 2012 and 2016 US presidential elections, European Journal of Marketing, vol. 53, issue. 12, pp 2629-2656, 2019. 